\title{
23\%3\%
}

\section{O fascismo e a economia politica}

Conferencia do sr. dr. Cardozo de Mello Neto, professor da Faculdade de Direito de S. Paulo, realizada no Instituto da Ordem dos Advogados Brasileiros em 19 de julho de 1930.

O individualismo e o socialismo constituiam, anteriormente á conflagração européa, as grandes correntes em que se bipartia o pensamento humano, ao encarar o phenomeno economico da troca das riquezas, o que vale dizer - o dominio da Economia Politica.

A corrente individualista, liberal ou classica, firmada no dogma da existencia de leis naturaes (relações necessarias derivadas da natureza das cousas), circumscreve as funç̧ões do Estado á producção de segurança.

A missão essencial do Estado, - aquella para a qual elle foi creado, e sem a qüal se não concebe sequer sua existencia, é a realização do direito: - no interior, pela manutenção da ordem juridica interna; no exterior pela defesa do territorio contra o inimigo externo. Dahi o principio da não intervenção na ordem economica: "o bem que o Estado faz, fal-o mal, o mal que faz, fal-o bem"

Reconhecer a existencia das leis naturaes e transformal-as em normas juridicas, eis a missão do legislador. 
Applical-as, administrando, é, no terreno economico, a missão do poder publico.

Essas leis não são contrarias á liberdade humana; ao invés, representam as relações que se estabelecem expontaneamente entre os homens vivendo em sociedade desde que indebita intervenção se não manifeste. Só nessa hypothese surge a harmonia dos interesses, que constitue precisamente a ordem natural e essencial das sociedades humanas, sempre superior a qualquer combinação artificial.

Donde, o direito do individuo - motor e fim da actividade economica - ao fructo integral de sua producção (actividade pessoal, resultado do trabalho anterior proprio ou alheio) á terra (propriedade privada), ao salario, ao juro, á renda.

Em consequencia, a desegualdade reconhecida entre os homens que nasceram physica, intellectual e moralmente deseguaes, a qual, longe de ser um mal, representa um beneficio, como condição que é do progresso social, porque o desejo humano de fazel-a desapparecer ou attenual-a, é o mais energico estimulante da producção.

Synthetizando: a escola individualista repousa nos principios juridicos - da liberdade individual, da propriedade privada, da successão particular dos meios de producção, e da liberdade de contractar.

Nenhum Estado, jámais, circumscreveu sua acção ás lindas traçadas pelos classicos. A historia o evidencía e os proprios individualistas o reconhecem, quando attribuem a imperfeição do actual estado social ao esquecimento das leis naturaes, ao desrespeito ao principio da liberdade de concurrencia. Em todos os tempos, affirmam-no, e é certo, os governos intervieram para regular as condições de producção, o movimento dos preços, os contractos relativos á mão de obra ou ao capital, as condições de troca entre os paizes; e essas multiplas regulamentações, comquanto com excellentes intuitos, não tiveram outro effeito senão contrariar o funccionamento natural das leis economicas, produ- 
zindo um grande mal definitivo, para conseguir um pequeno bem, transitorio, e, ás vezes, de pura illusão.

Apesar disso, porém, ou por isso mesmo, eis que tal intervenção nem sempre se norteou por principios, houve em todo o tempo quem - os utopistas - pugnando pela egualdade "de facto" entre os homens, não se contentasse com a egualdade "juridica", a egualdade dos direitos estabelecida, de ha muito, nas constituições politicas dos povos. Em - Les égaux - se encontra a genesis do socialismo.

Mas, a idéa igualitaria não é, por si só, sufficiente para caracterizal-o. Os socialistas surgem no momento em que a socialização dos bens, pela suppressão da propriedade privada, fixa o meio de realização da igualdade de facto.

Dahi o vocabulo - socialismo, que não significa senão o meio para a realização de um fim - a igualdade de facto entre os homens.

“A idéa igualitaria, a suppressão da propriedade pela socialização da economia, taes parecem ser a alma e a forma do socialismo, seu espirito e seu meio de acção, os dois traços, um interno, outro externo, que, reunidos, formam - o socialismo" E' a conclusão de Deschamps, que assim lapidarmente o define: "a doutrina que, tendo em vista estabelecer e fazer reinar a igualdade das condições, quer supprimir a propriedade e socializar a economia"

O communismo é a forma tradicional, primitiva, do socialismo. Supprime a propriedade privada tanto em relação aos agentes-terra, trabalho e capital, como aos fructos da producção. A utilidade criada pela communhão, por ella deve ser consumida, distribuindo-se-a entre todos, em partes iguaes, ou dando-se a cada um segundo suas necessidades.

O collectivismo, outra forma do socialismo, ao contrario do simplismo communista, tem sua philosophia - a de KARL MaRX.

Parte elle da idéa de que a organização social é dominada inteiramente pelo meio economico, isto é - de que todas as transformações sociaes são condicionadas por factos economicos, e exclusivamente por elles. Foi assim no appa- 
recimento do Christianismo; foi esse o motivo das invasões barbaras, da suppressão da escravidão e do desapparecimento do feudalismo. 0 facto que dá logar, que serve de ponto de partida a todas as successivas phases da evolução social, é sempre o mesmo: a lucta das classes para a melhoria de suas condições economicas, a conquista da riqueza e do bem estar. E a historia sempre offerece o mesmo espectaculo: o triumpho final da classe mais numerosa e menos aquinhoada sobre a classe menos numerosa e mais rica. E' a lei da evolução social. Foi assim no passado, será assim no futuro. Actualmente, é a classe burgueza que detem o poder economico - o conjuncto dos bens destinados á producção. Em face dessa classe surge, ameaçadora, a que menos possue - o proletariado. Essa lucta é a consequencia da ruptura de harmonia, que cada vez se vae accentuando mais, entre o modo de producção da riqueza e o de sua apropriação. Ao passo que o modo de producção cessou de ser individual, tornou-se collectivo com a substituição do braço pela machina, do individuo pela fabrica, o modo de apropriação continua individual, pela manutenção, inexplicavel, da propriedade privada.

A consequencia é faltal: a lucta dos proletarios, que produzem collectivamente e não possuem, com os capitalistas, que não produzem e possuem individualmente. A lucta continuará até que a harmonia se restabeleça pela transformação do modo de apropriação dos bens. E o proletariado triumphará marcando a ultima phase da evolução social: o collectivismo.

O caracter particular do marxismo está em que, emquanto os demais systemas socialistas fundam suas reivindicações no ideal de Justiça, Marx desdenha essas construcções, consideradas utopicas, pretendendo que a sociedade nova surgirá do simples jogo das leis economicas, pelo effeito da evolução social determinada exclusivamente pela conquista da riqueza e do bem estar. Sua concepção ma- 
terialista nega a existencia de factores de ordem ideologica, taes como o amor á liberdade e o sentimento da justiça. $\mathbf{E}$ nisso se resume o socialismo.

As outras escolas appellidadas socialistas não são senão doutrinas ecleticas, mais approximadas do liberalismo que do socialismo, porque nellas a propriedade privada permanece, ainda que condicionada, quando (a observação é de Deschamps) o socialismo representa, ao contrario, o protesto permanente contra um estado social fundado, em todos os tempos, sobre a propriedade privada.

Dentre ellas cumpre destacar, por sua influencia decisiva no destino dos povos, o socialismo d'Estado e sua doutrinalização - o solidarismo.

Não é o socialismo d'Estado senão uma politica: a que consiste em querer dar satisfação ao maior numero dos desiderata do socialismo pela acção do Estado, cuja base juridica e social é integralmente mantida. A elle devemos, não só a regulamentação das relações entre o trabalho e o capital, como as medidas de assistencia obrigatoria e legal reunidas sob a denominação de - legislação social, como a estatização ou municipalização, de certas industrias, seja no intuito de augmentar o dominio dos monopolios fiscaes, ou no de fornecer ao publico certos serviços por preços inferiores aos exigidos pela industria privada. Sua arma favorita é o imposto directo que, perdendo seu primitivo caracter, é manejado no sentido de tirar aos que têm de mais, afim de dar aos que possuem de menos, - para consecução daquella igualdade na riqueza e na miseria, que aflora aos labios e está no espirito de todos os socialistas.

Implantando-se na França, a politica social encontrou em Leon Bourgeois o seu doutrinador. O solidarismo, ou theoria da divida social, a mais elegante concepção philosophica dos tempos modernos, transforma essa politica 
numa doutrina, a qual, dando como provadas, ao mesmo tempo, duas leis antitheticas - a lei da concorrencia vital e da selecção natural, base do individualismo, e - a lei da solidariedade das differentes partes do organismo social (oriunda esta da biologia) pela qual se chega ao socialismo, - procura coincilial-as sob a égide da noção de Justiça.

Taes as concepções economicas, antes que o mundo tivesse sido abalado pela grande guerra.

O fascismo e o bolchevismo são os dois phenomenos caracteristicos do após guerra.

"Serão manifestações de decadencia duma civilização esgotada, ou signaes precursores, duma nova civilização, visando a conquista do mundo, graças á disciplina das massas submettidas ao poder absoluto do Estado e de seus dirigentes"? E' a pergunta que a si mesmo se faz Francisco Ferrari, na sua monumental obra "Le regime fasciste italien"

Que o julgue quem para isso se sentir habilitado. 0 que de nós se vae ouvir é apenas um breve e modestissimo ensaio, collimando apenas o objectivo de vêr entre nós ventilado pelos doutos problema assim actual, como indispensavel á vida dos povos, e a cujo estudo é impossivel furtarmo-nos não tanto por interesse doutrinario como, e principalmente, por sentimento de patriotismo.

O bolchevismo venceu na Russia como o partido das reivindicações maximas, que buscava sua base, ora no communismo, ora no marxismo. Mas não foi, nem é, na poli-. tica russa, uma ou outra coisa.

Não é o communismo, porque este seria a collectividade toda inteira organizada para a producção, distribuida, posteriormente, a todos igualmente, e o bolchevismo nunca foi isso, nem mesmo em sua inicial applicação. 0 soviet, que se substitue ao Estado, é uma organização de operarios, 
camponezes e soldados, isto é - da classe tornada revolucionaria pelos meneurs de má fé, unida á força, procurada porque indispensavel á garantia da exploração da riqueza.

Não é tão pouco o collectivismo de KARL MARx, apesar de ter tirado deste a idéa essencial e destructiva, da lucta das classes, até o advento da catastrophe final (a these catastrophica), porque jámais pretendeu separar a riqueza de producção da de consumo, fazendo a distribuição desta pelo criterio de "a cada um segundo seu trabalho" - outra idéa essencial, constructiva esta, do marxismo.

Que é então o bolchevismo?

Duas épocas distinctas marca a politica maximalista.

A anterior a 1922 foi uma pretendida applicação do communismo, sob a base e direcção de um Estado sui generis - o soviet. Essa, falliu: os factos o evidenciam, e os proprios bolchevistas o confessam.

Sob seus escombros surgiu uma nova politica - a "NEP" Essa não é communista, "apesar de suas apparencias socialistas, é essencialmente reaccionaria", de tal arte que, sob o ponto de vista economico (para só nos circumscrevermos a elle, e não levantarmos o véo das miserias no campo do Direito, que naufragou, e da Moral que, envergonhada, se escondeu) a Russia actual está dividida em dois sectores: a economia estatizada e a economia privada.

A industria nacionalizada, os transportes nacionalizados, o monopolio do Estado no commercio exterior, o commercio interno organizado pelo Estado, e a cooperação controlada pelo Estado em materia de creditos, constituem o primeiro sector. $O$ numero de pessoas nella occupadas não vae além da sexta parte da população.

A outra, a economia privada, é composta de 25 milhões de pequenas explorações ruraes, de quasi meio milhão de pequenas empresas commerciaes, e duma classe nova de novos burguezes e capitalista que, não sendo nem os burguezes nem os capitalista do Tzar, desempenham o mesmo pa- 
pel delles: são os proprietarios de immoveis, os grandes representantes das finanças, os enriquecidos intermediarios de emprestimos, aos quaes teve de recorrer a Russia communista.

Na phrase de Simon Zagarsk (antigo professor de E. Politica na Universidade de Petrograd) a economia estatizada não representa senão uma pequena ilha perdida no oceano immenso das economias privadas.

A experiencia dolorosa vem demonstrando que o surto da economia estatizada depende do desenvolvimento da economia privada. Apesar de seus ingentes esforços, a Russia sovietica não se tem bastado a si mesma: a desigualdade inherente á natureza humana, passada a borrasca, já se fez nitidamente sentir.

Donde, e a observação é do mesmo professor, não ha, na hora actual, senão duas soluções para o problema russo: - a volta ao communismo, ou o reconhecimento e consolidação, na legislação, dos novos direitos adquiridos pelas novas classes sociaes.

A primeira solução, preconizada pelo grupo constituido pelos eternos descontentes, não tem adeptos entre os bolchevistas responsaveis. Ella se baseia no argumento de que o communismo falliu na Russia porque o proletariado nacional não foi ajudado por seus irmãos, espalhados pelo mundo. Dahi o prégarem a necessidade de uma revolução communista mundial, graças á qual todos os paizes tornados communistas, baseando-se na solidariedade internacional, terão de ajudar a Russia a vencer as difficuldades economicas actuaes.

Pertence a essa corrente, irresponsavel, o communismo que se espalha na Europa e procura invadir a America. Não olvidem os operarios, inclusive os nossos, que seus meneurs fazem a propaganda de um systema que já falliu no paiz de origem.

A' outra solução - que é a normal - não se poderá chegar senão por meio do reconhecimento da propriedade privada. "De instituição já tolerada e excepcional, o di- 
reito de propriedade privada deve tornar-se o principio essencial e a base fundamental da nova sociedade russa.

$\mathrm{O}$ direito de propriedade e o direito á iniciativa privada, a liberdade individual e a economica, taes são as bases indispensaveis, sobre as quaes deve ser fundada a democracia russa. Fazel-a reconhecer e sanccionar pela legislação, será o ultimo acto da revolução russa, para completar sua obra. (S. Zagorsky, Ou va la Russie?).

Tomemos o fascismo, então fascios de combate, em 1919. Seus propositos eram de verdadeira subversão da ordem politica e economica da Italia. Na verdade, $?$ programma fascista dessa época continha. na ordem politica, a svaticanizzazzione e o confisco de toda a propriedade ecclesiastica, e a constituição da republica italiana. O meio - a convocação de uma assembléa constituinte italiana, concebida com a secção italiana da constituinte internacional dos povos, para desta surgir a transformação radical das bases politicas e economicas da vida social (art. $1^{\circ}$ ). A nova republica italiana devia ser fundada sobre a soberania popular exercida pelo suffragio universal directo dos cidadãos de ambos os sexos (art. $3 .^{\circ}$ ). O poder legislativo devia ser confiado a uma só Camara, abolido o Senado, como limitação arbitraria e artificiosa da soberania popular (art. $3 .^{\circ}$ ). As funcções executivas do Estado deviam se limitar á direcção civil e politica da vida nacional (art. 2..$^{\circ}$ sob a base ae uma descentralização politica e administrativa. Pedia-se, outrosim a extirpação da burocracia irresponsavel, a abolição da policia politica e a creação dos juizes electivos (art. $3 .^{\circ}$ ).

Todas as liberdades seriam reivindicadas, a saber: as liberdades de pensamento, de consciencia, de religião, de associação, de imprensa, de propaganda, de toda iniciativa individual e de todo movimento collectivo (art. 6..$^{\circ}$; ao 
mesmo passo que se proclamava a necessidade da instauração de um systema de rigido monopolio do ensino (art. 7.0).

A politica economica devia se fundar nas bases seguintes: - dissolução das sociedades anonymas, industriaes e financeiras; suppressão de toda especie de especulação dos bancos e das bolsas; criação de um organismo nacional, com secções regionaes, para distribuição do credito (art. 9..$^{\circ}$; recenseamento e redistribuição da riqueza nacional; pagamento da divida do Estado á custa dos ricos (art. 10. ${ }^{\circ}$ ); a terra confiada aos camponezes; a exploração de todas as industrias, incluidas as de transportes e as de serviços publicos, confiada aos syndicatos de technicos e trabalhadores $\left(\right.$ art. $\left.3 .^{\circ}\right)$.

A politica internacional devia inspirar-se no principio de solidariedade dos povos, e de sua independencia no seio da confederação dos Estados (art 14. ${ }^{\circ}$ ).

Como se vê, um programma proprio para interessar 0 povo italiano, esgotado politica e economicamente. Politicamente, porque os partidos incompatibilizados entre si e todos com o povo, estavam se mostrando impotentes para resolver a formidavel crise politica de após guerra. $\mathrm{E}$, inconscientes do papel historico que eram chamados a desempenhar, reduziam-se a procurar resolver as situações que surgiam de momento a momento pelo criterio estreito do mais estreito partidarismo. Economicamente, porque a Italia dia a dia empobrecia, sitiada por um lado pela velha classe dirigente, educada na escola do compromisso, não comprehendendo nem a extensão, nem a significação da crise, e esperando ainda conter os excessos das classes operarias pelos habituaes expedientes de policia; e de outro, pelo operariado, embebido das idéias maximalistas, procurando tudo destruir, sem nada saber ou poder construir, esperando o remedio de uma revolução que se iniciaria com a chegada dos exercitos bolchevistas do Occidente. E, entre uma e outra, a burguezia que "sem uma consciencia robusta e uma cultura seria, permanecia impotente em face dos acontecimentos" 
'Todo o mundo comprehendia que a reacção viria mais dia, menos dia. Sufficiente, apenas, que surgisse um centro e uma direcção; um homem, emfim. Esse homem foi Mussolini; esse centro o fascismo.

O fascismo comprehendeu a situação. Para tomar a direcção da Italia era preciso pôr-se á frente dum movimento anti-socialista; - o fascismo renunciou o programma de 1919 e se fez anti-socialista. De fascios de combate, transforma-se no Congresso de Roma (Nov. 1921) em partido politico. Proclama o estabelecimento do dominio da lei, a volta aos principios do liberalismo economico, recebendo assim a enthusiasta adhesão da alta burguezia de Emilia, da Romagne, e da Lombardia, para a qual o liberalismo constituia não só uma velha tradição como a melhor garantia de sua riqueza crescente. No seu movimento, vae envolvendo a Italia toda inteira, de norte a sul, quebrando todas as resistencias, aliás fracas do partido socialista, porque desmoralizado com a experiencia (estamos em 1921) communista que fallira na Russia, tanto pela cessação quasi integral da producção (desde que os novos proprietarios tinham verificado que a producção era propriedade do Soviet e não do trabalhador) como pelo resultado nefasto da occupação das usinas.

Mas, para vencer não bastava, na occasião, ser anti-socialista. "Mussolini percebeu que sua milicia, que se glorificava, como duma grande victoria, da perseguição das forças socialistas em debandada, não teria a cohesão e o "entrain" sufficientes para fazer face ao exercito regular, ainda que as tendencias philofascistas de muitos officiaes não fizessem prever senão uma fraca resistencia" (FERrari).

E o fascismo approximou-se solennemente da Monarchia. Seu chefe, em discurso memoravel, rende homenagem ao Rei, "primeiro soldado da Italia"

Emquanto o fascismo quebra assim todas as resistencias para acaparar o poder, a politica profissional, sem norte, progressivamente se enfraquece e definitivamente se desmoraliza. O resultado era fatal, e é assás conhecido: 
- a marcha sobre Roma - verdadeira parada militar; o chefe do fascismo, Primeiro Ministro da Italia.

Eil-o no poder. Seu programma até aquelle momento, fôra o de esmagar o communismo na Italia, e este estava realizado. $O$ de restabelecer a ordem publica, e esta estava restabelecida, ainda que a custa das liberdades publicas, mas estava restabelecida.

O fascismo, porém, não se tinha alçado ao poder para, como méro partido politico, governar dentro da antiga ordem de coisas. Seu fim consistia em "levar o povo italiano á realização de seu destino historico" Para tal era mistèr infiltrar a idéia fascista na consciencia e na alma de cada cidadão, fazendo de todo italiano, um fascista. $O$ meio transfundir a idéia de Patria na de fascismo; a noção de Direito, na de fascismo: as leis da Economia Politica nas do fascismo. Criar um Estado fascista, um Direito fascista, uma Economia Politica fascista. Um Estado, emfim, como proclama Rocco, o legislador do regime, que contivesse em si todos os elementos das antigas concepções juridicas e economicas e a todas superasse.

Delle são essas memoraveis proposições:

"O Estado fascista contem o liberalismo, e o supera: contem-no porque se serve da liberdade, quando essa é util; supera-o porque refrea a liberdade quando essa é damnosa. O Estado fascista contem a democracia e a supera: contemna porque faz o povo participar da vida do Estado, na medida do necessario; supera-a porque reserva-se a possibilidade de fazer decidir os problemas essenciaes da vida do Estado pelos homens que tem a capacidade de comprehendelos sobrepondo-se ás considerações dos interesses contigentes dos individuos. Finalmente, o Estado fascista contem o socialismo e o supera: contem-no porque quer como este realizar a justiça social; supera-o porque não consente que essa justiça seja feita mediante o surto brutal da força social, nem crê ser necessario para collimal-a um mastodontico e complicado systema de producção collectiva, que acabaria 
por supprimir todo espirito de economia e absorver o util do processo productivo"

O nacionalismo fascista funda toda sua doutrina na seguinte concepção:

“A humanidade existe como facto biologico, não como idéia social. Ao contrario, as sociedades humanas particulares são a um tempo, um facto biologico e uma concepção social, são fracções da especie humana, providas duma organização unitaria destinada á realização dos fins proprios da especie" (Rocco, discurso na Univ. de Perouse).

Assim, as unicas realidades sociaes são as sociedades humanas particulares, ou as nações. Estas, sómente, é que têm fins caracteristicos. Donde, o individuo não tem dever algum para a humanidade e unicamente para com a nação, que a carta do trabalho define: "um organismo tendo fins, vida e meios de acção superiores em poder e duração aos dos individuos isolados ou associados que a compõem; uma unidade moral, politica e economica que é integralmente realizada no Estado fascista" (Art. $1^{\circ}$ )

Todos os deveres do individuo se concentram na sua submissão á nação, ou, melhor, ao Estado, que a encarna e representa, porque "a sociedade é que é o fim, e o individuo o meio; o fim do Estado é o de transformar os individuos em instrumento dos fins sociaes". (Rocco, loc. cit.) Submissão natural porque "a nação é divina, é a expressão concreta dum movimento progressivo de transformação do espirito, e por consequencia contem em si o genero e a especie; é a synthese do universal e do individual, encerrando em si as razões de nosso direito e do nosso dever, a razão da extensão e limites de nossa individualidade" (Balbino Guigliano). Synthese: (é Mussolini quem a faz):

"Tudo para o Estado, nada fóra do Estado, e sobretudo nada contra o Estado"

Numa sociedade assim concebida, o direito natural não póde existir. E na verdade não é reconhecido: "o direito sómente surge pela declaração do Estado. O Estado fascista é a unica fonte de direito, a unica origem da justiça. 
A lei é justa porque é dictada pelo Estado e ninguem póde contestar sua legitimidade pretendendo a violação de qualquer direito natural"

Mas, que é a nação fascista? Quem dirige o Estado fascista? $O$ conjuncto de individuos vivendo sobre o mesmo solo, pertencendo a mesma raça, falando a mesma lingua, tendo os mesmos interesses?

Não, respondem: "Os individuos que compõem a nação são incapazes, tanto individual como collectivamente, de determinarem os verdadeiros fins da sociedade. Sómente os homens capazes têm o direito de dirigir a acção do Estado no sentido de seus interesses legitimos. A multidão não tem a capacidade necessaria para apreciar o bem commum, nem é capaz de escolher os chefes, encarregados de sua realização. Em consequencia, o Estado deve ser dirigido por homens excepcionaes que, por seu genio transcendente, possam informar toda a acção do Estado. A vontade desses homens póde, legitimamente, impôr-se ás tendencias contrarias da multidão porque, identificada com a do Estado, participa de sua divindade e do seu poder sem contraste"

Será mister respigar mais na seara fascista para fazer resaltar que tal regime se chama absolutismo e um Estado assim formado não é senão a divinização e a organização da dictadura?

A organização economica do fascismo é apenas uma consequencia logica dos fins attribuidos ao Estado-Nação. Duas questões, igualmente essenciaes, preoccupam o Estado fascista - a relativa ás relações entre o capital e o trabalho, isto é - a questão social; e a referente á intensificação e aperfeiçoamento da producção nacional.

A primeira é posta nos seguintes termos:

O problema das relações entre o capital e a mão de obra tem sua origem na usina. Até o principio do seculo 18 o 
problema era desconhecido. $O$ operario, na pequena industria, trabalhava por sua conta: era o systema do empresario-operario. Era, as mais das vezes, não sómente um artifice, mas um artista; seu trabalho não constitua simplesmente o seu ganha pão mas um prazer; a organização do trabalho, uma fonte de harmonia e de tranquillidade. A grande industria representada pela usina, transmudou a face das coisas. A introducção das machinas e o principio da divisão do trabalho, levado ao extremo, tornaram mecanico e monotono o trabalho do operario manual. Os novos operarios se encontraram em condições essencialmente differentes dos artistas dos seculos passados. Ao mesmo tempo, para manejar as grandes empresas tornavam-se necessarios grandes capitaes, e cerebros organizadores e directores da exploração. A separação entre o patrão e o operario fixou-se nitida. Fechado nos grandes estabelecimentos, repetia o operario centenas e milhares de vezes o mesmo gesto, tornado assim automatico. Seu trabalho passou a ser pura fadiga, simples meio de subsistencia material. Isto sob o ponto de vista moral. Economicamente, o resultado não se mostrava menos desastroso. A tendencia do salario era para uma progressiva diminuição resultante do augmento do numero de trabalhadores que, abandonando o campo, procuravam a usina. Da constatação desse facto, a lei de ferro dos salarios, de Ricardo. E, em meio disso, os capitalistas abusando cada vez mais da situação.

Por esse tempo o Estado, guiado pelos principios do liberalismo, brilhava pela ausencia; sua pretensa neutralidade entre os fortes e os fracos favorecia os primeiros em detrimento dos segundos. Dahi, o socialismo que não é senão a lucta das classes e das categorias, - a auto-defesa dos operarios abandonados pelo poder publico, pela parede, a principio simples meio de lucta economica, transformada mais tarde em arma politica tendente a criar um estado de desordem e de agitação. E o Estado-liberal continuava, impotente, a assistir á lucta de todos contra todos, isto é, ao desencadeamento da guerra civil, e da anarchia, eis que a 
idéa de lucta de classe se ampliou de uma maneira desmesurada ao ponto de abraçar as relações entre o Estado e os seus agentes, como se a Nação constituisse uma classe contra a qual fosse permittido combater em nome de interesses particulares. Essa a situação da Italia após a guerra, a qual persiste ainda hoje em outros paizes. São todas idéas e palavras da exposição ministerial apresentada á Camara dos Deputados.

Dahi a necessidade de criar-se um syndicalismo particular, fascista, nitidamente distincto do syndicalismo-socialista.

Substituir a lucta das classes pela organização dos grupos e categorias. Despir o syndicalismo de todas as ideologias anti-nacionalistas, internacionaes, pacifistas, humanitaristas, e integral-o na idéa de Patria e de solidariedade nacional. $O$ socialismo baseia-se na solidariedade internacional das classes e nega a solidariedade nacional. Nós (a phrase é de Rocco) invertemos os termos do problema: “á lucta das classes na solidariedade internacional oppomos a solidariedade das classes na lucta internacional"

A outra questão - a da producção, é peculiar á Italia. O nacionalismo fascista parte do principio, elevado á categoria de um postulado insusceptivel de demonstração, de que "na Italia a questão social é sobretudo um problema de producção." E' um povo pobre de meios, mas rico de vidas e de vontades cujo dever é de marchar para diante como um exercito disposto em ordem de batalha. $E$ porque se trata de direcção de um exercito de pobres para a conquista dos meios de producção, tudo se deve e póde esperar do Estado.

A questão social se resolverá unicamente por medidas legislativas, baseadas nas idéas de supremacia do EstadoNação. Assim como a marcha sobre Roma matou o communismo, e restabeleceu a ordem, a organização ferrea, militar, da producção nacional salvará a Italia, e a reintegrará no seu destino historico. 
Essa organização "marcará o fim dum periodo historico e o começo dum novo: a passagem da civilização industrial moderna, com seus desequilibrios e suas desordens, para a phase da estabilidade sob uma disciplina harmoniosa e organica" (Rocco)

Como se consegue esse ideal?

Pela volta á antigas corporações, como muitos preconisavam? Não "porque essa é uma organização rigida e schematica, sem nenhuma possibilidade de livre desenvolvimento" Entendemos, por isso, que uma incorporação assim de toda população não corresponde ás condições actuaes da vida italiana. Preferivel será partir dum facto existente da realidade, isto é - dos syndicatos".

A reforma urganica, a "nova politica economica", surge baseada nos principios da "Carta del Lavoro".

Quatro pontos fundamentaes, contem a reforma: - o reconhecimento e a disciplina juridica dos syndicatos; - a regulamentação dos contractos collectivos de trabalho, - a instituição de um orgam judiciario para derimir os conflictos do trabalho, e - a interdicção da parede e do "lockout" As condições de reconhecimento, funccionamento e as attribuições dos syndicatos são, resumidamente, estas:

a) - Em cada circumscripção territorial, sómente um syndicato é reconhecido para cada categoria profissional de patrões e operarios.

b) - Os syndicatos reconhecidos representam legalmente, na sua circumscripção, todos os patrões e operarios, inclusive aquelles que não adheriram ao syndicato, e não se inscreveram.

c) - Os syndicatos têm o direito de lançar sobre todos, mesmo sobre os patrões e operarios não inscriptos, uma contribuição annual, - obrigatoria como o imposto, exigivel pela maneira por que este o é.

d) - Os syndicatos patronaes e os syndicatos operarios podem ser reconhecidos separadamente. 
e) - Podem ser reconhecidos não sómente os syndicatos de patrões e operarios como os formados por pessoas que exercem qualquer profissão.

f) - O syndicato legalmente reconhecido é submettido ao contrôlo continuo do Estado. A nomeação do presidente e secretario é approvada pelo Estado, seu conselho de administração póde ser dissolvido a qualquer momento. $\mathrm{O}$ reconhecimento legal, que lhe dá existencia juridica, póde ser retirado, desde que elle se afaste de suas attribuições normaes. Nesse caso um commissario do governo dirige o syndicato.

g) - O syndicato não se póde limitar ao objectivo puramente economico, mas deve exercer funcções de assistencia, de instrucção, de educação moral e patriotica. Todos seus membros devem dar garantias de sua capacidade, de sua moralidade e de seu patriotismo.

h) - São expressamente vedadas as organizações de syndicatos de empregados publicos - do Estado, das provincias e das communas.

Reconhecem os fascistas que em nenhum paiz as associações syndicaes são submettidas a um contrôlo tão rigoroso do Estado. Mas a razão dão-na lealmente:

- O syndicato é um orgam de direito publico, e, pois, tem necessariamente de ser unico. "Como orgam de direito publico, os syndicatos velam pelos interesses materiaes e moraes immediatos das categorias que representam, mas não devem jamais perder de vista o interesse superior da producção, e o do paiz, que deve ser o primeiro e constante cuidado de todos e de cada um"

“ $E$ ' evidente que o Estado fascista não pode permittir que, em dado momento, aproveitando-se de circumstancias favoraveis, uma certa categoria de cidadãos imponha sua vontade á Nação personificada no governo. O Estado tem obrigação, pois, de neutralizar e immobilizar as forças susceptiveis de pôr em perigo o interesse superior do paiz" 
Dahi a organização ferrea dos syndicatos imposta pela lei. E, mais, o que não está na lei, porém que Belloni faz questão de tornar claro, no seu famoso parecer na Camara dos Deputados:

“ $E$ ' preciso não esquecer que as pessoas dirigentes das associações devem gosar duma maneira permanente da confiança do governo. E' a melhor garantia de que o funccionamento della é conforme ao seu fim. Não haverá assim necessidade de submetter cada um de seus actos e deliberações a um minucioso exame"

A regulamentação juridica do contracto collectivo do trabalho é um consectario logico da regulamentação juridica dos syndicatos.

"Os contractos collectivos de trabalho estabelecidos pelas associações de patrões, operarios, artistas e outras pessoas exercendo uma profissão liberal legalmente reconhecida, são obrigatorios para todos os patrões, operarios, artistas e pessoas exercendo uma profissão liberal da categoria á qual o contracto collectivo se refere, e que essas associações representam" (art. 10, lei 3, de abril, 1926).

Os motivos de ordem economica dados para estabelecer a obrigatoriedade dos contractos collectivos de trabalho "erga omnes" são de extrema pobreza.

A's formidaveis objeções levantadas contra a obrigatoriedade, baseadas todas na impossibilidade de estandartizar dest'arte o trabalho, que não ficaria remunerado de então em diante segundo as respectivas capacidades, o fascismo responde, sem resolver a questão, que "o contracto collectivo não quer dizer necessariamente nivellamento igual e absoluto das condições, e que é sempre possivel prever, em um accordo collectivo, regras e condições particulares para certas empresas e certos sub-grupos de producção"

Mas é força reconhecer que o fascismo se mostra, nesse dominio, perfeitamente coherente. O seu ponto de vista é o augmento da producção mesmo á custa dos proprios trabalhadores: - $O$ "Estado é o fim, os individuos o meio". Para esse augmento de producção, ha necessidade da tu- 
tela do Estado, e essa só pode ser efficaz obrigando a todos, a todos nivelando. Se injustiça houver será puramente individual. Porque, sendo o trabalho uma obrigação juridica e politica, se alguem no contracto collectivo fôr realmente prejudicado, injustiça social não haverá eis que o individuo trabalhou para o Estado, cujos interesses são muito superiores aos seus.

Para derimir todas as duvidas relativas ás relações collectivas do trabalho, após uma tentativa de conciliação, criou-se um tribunal especial de trabalho.

Mas, o tribunal não limita sua intervenção á solução das duvidas surgidas por occasião da applicação dos contractos, livremente estipulados - funcção judiciaria. Seu poder vae além: estatue sobre os conflictos de ordem economica, nos quaes as partes não invocam em seu favor a applicação do direito, mas "estão em lucta a respeito da constituição de certos direitos subjectivos" A intervenção, nesse caso, do tribunal não é justificada pelos principios juridicos que regem a decisão dos litigios entre particulares, mas "por principios de ordem social e politica que encontram sua explicação na natureza particular dos conflictos collectivos e na repercussão que o desaccordo das partes produz na vida do paiz" Porque, nesse caso, o desaccordo dá em resultado "uma inacção das forças e dos meios de producção do paiz, e uma falta de trabalho, mais ou menos consideravel, de desastrosas consequencias economicas e sociaes"

Comprehende-se bem nessas poucas expressões, a força e poder do magistrado do trabalho.

Juiz que não julga segundo a lei escripta, nem o costume, e não tem condições de independencia, não é, em summa, senão um delegado do poder executivo encarregado de impor contractos de trabalho, segundo a vontade deste, vestida com o tecido transparente do "supremo interesse da producção nacional"

Em consequencia, a parede e o lock-out são delictos analogos ao exercicio arbitrario dos direitos. 
Se ha uma magistratura do trabalho, não tem o patrão, nem o operario, o direito de fazerem a sua auto-defesa, pela parede ou pelo lock-out.

Assim como, nas relações privadas, não se admitte mais a auto-defesa, da qual se encarrega o Estado, assim tambem nas relações sociaes e economicas, toda auto-defesa é um acto anti-social, anti-economico, passivel de pena.

Eis ahi, em larguissimos traços, a organização economica calcada na "carta do trabalho".

E' ou não a organização da dictadura, na ordem economica? Approxima-se ou não dos desejos dos communistas mais extremados?

"O syndicato unico, a exclusão da vida syndical e da vida civil dos adviersarios do regimen, a direcção estatizada da organização profissional, a dictadura da elite politica depositaria unica do novo evangelho, o controlo do Estado sobre toda a producção nacional, sobre o credito, sobre as empresas privadas, sobre o commercio, nada falta na organização corporativa italiana" (Ferraris).

Tudo é feito no proposito de dominar, sem contraste. Basta um relancear de olhos nas leis posteriores á "carta", para sentir o absolutismo do Estado-Nação, do homem providencial. No dominio do credito, fez-se a unificação dos bancos de emissão, o que foi um beneficio, mas ao mesmo tempo opera-se a fascistização dos conselhos de administração e das direcções dos bancos.

As bolsas são submettidas ao controlo do Estado. Um regimen especial é estabelecido para as sociedades anonymas, que todas carecem de autorização para funccionar, a qual pode ser recusada e cassada a qualquer momento, ficando assim nas mãos do Governo a possibilidade de instituir quaesquer monopolios.

De 1927 para cá, o governo começou a exercer sua acção directa sobre as industrias. Mas, para pol-as ao sabor do Estado sufficiente jâ era a carta do trabalho, e o regimen das sociedades anonymas. 
A politica intervencionista não poupou a agricultura. Porém, é no dominio do commercio que ora se exerce com mais força a acção do Estado fascista.

"O commercio exterior está submettido a uma quantidade de prohibições e toda a materia de defesa da importação e da exportação, está confiada ao poder arbitrario do Ministro das Finanças, de sorte que o exportador, antes de estudar os mercados estrangeiros que elle quer conquistar, deve estar seguro da protecção e da benevolencia dos funccionarios do Ministerio"

No commercio interno, voltou-se ao systema das licenças do antigo regimen que são, em geral, negadas, porque o proposito é de fomentar a criação de grandes empresas industriaes, que possam, com facilidade, ser fiscalizadas pelo governo.

Serão manifestações de decadencia de uma civilização esgotada, ou signaes precursores de uma nova civilização? Que o julguem os doutos.

Para nós, o fascismo é a anthithese da democracia, o desconhecimento da existencia de leis economicas, ineluctaveis, a negação do Direito e a enthronização da força. 